\title{
PRÁTICAS PARA APRIMORAR O ENSINO NA DISCIPLINA DE PEDOLOGIA
}

\author{
Practices to improve teaching in pedology discipline
}

\author{
BATISTA ${ }^{1}$, I. S.; SILVA ${ }^{1}$, R. Q.; ARAÚJO ${ }^{1}$, I. S.; BATISTA ${ }^{2}$, I. S.; LIMA ${ }^{3}$, Z. M. C. \\ ivanizas@ymail.com;
}

\begin{abstract}
Resumo
A Pedologia é uma ciência de suma importância na compreensão, análise, interpretação e planejamento do espaço geográfico. Diante disso, torna-se relevante que o ensino da Pedologia proporcione condições reais de aprendizado e construção do conhecimento. Objetivou-se avaliar a importância da utilização de atividades práticas para aprimorar o ensino em Pedologia. A metodologia adotada restringiu-se à aplicação de questionários e a realização de uma avaliação das experiências adquiridas em sala de aula. Os resultados obtidos demonstram o quão relevante se constitui o desenvolvimento de atividades práticas como essa. Os alunos puderam analisar em campo e em laboratório os atributos morfológicos dos solos e discutir as peculiaridades de cada um deles, fazendo inferências sobre os diferentes ambientes de onde as amostras de solo analisadas foram coletadas. Por fim, foi comprovado a partir da análise dos questionários que os discentes demonstraram aprender com maior facilidade os conteúdos teóricos trabalhados em sala de aula, em campo e com a ida ao laboratório. Essas práticas capacita-os a analisar das particularidades dos solos e suas inter-relações com o meio, de modo, a aguçar o olhar técnico/profissional dos mesmos.
\end{abstract}

\begin{abstract}
The Pedology is a science of the utmost importance in understanding, analysis, interpretation and planning of geographical space. Thus, it becomes important that the teaching of Pedology provide actual conditions of learning and construction the knowledge. Objective to evaluate the importance of the use of practical activities to improve teaching in Pedology. The methodology adopted was restricted the application of questionnaires and conducting an assessment of the experience gained in the classroom. The results obtained show how relevant is the development of practical activities. The students were able to analyze in the field and in the laboratory the morphological attributes of soils and discuss the peculiarities of each of them, making inferences about the different environments where the soil samples analyzed were collected. Finally, it has been proven from the analysis of the questionnaires that the students showed learning with greater ease the theoretical contents worked in the classroom, on the field and with the trip to the lab. These practices enable them to analyse the peculiarities of the soils and their interrelations with the environment, so as to sharpen the technical/professional look.
\end{abstract}

Keywords: Pedology.Practical activities. Teaching.

\section{INTRODUÇÃO}

A Pedologia constitui-se como uma ciência de caráter relevante na análise e interpretação dos distintos ambientes encontrados na Terra, proporcionando conhecimentos básicos e elementares para a compreensão e planejamento do espaço geográfico. "Etimologicamente, a Pedologia é um nome erudito construído pela adição de PEDON (lugar ou solo onde se pisa) a LOGOS (discurso ou razão); [...] Assim a Pedologia seria o discurso do solo.” (QUEIROZ NETO, 2011, p. 95). Trata-se de um ramo do conhecimento relativamente recente, também conhecida como à Ciência do Solo (IBGE, 2007).

Entende-se por solo a camada superficial constituída por partículas tanto minerais quanto 
orgânicas, distribuídas em sessões verticais com profundidade variável, sendo resultado da ação de agentes intempéricos sobre as rochas, assim como, da adaptação das condições de equilíbrio do meio em que se encontram expostas ao intemperismo (EMBRAPA, 2014).

Dessa forma, a Pedologia é a ciência que estuda a parte superficial do solo que está sendo constantemente apropriada aos condicionantes climáticos e à atuação da fauna, flora e ação antrópica. A mesma, é essencial na formação profissional do geógrafo, do professor de Geografia e profissionais afins, pois proporciona condições fundamentais para o entendimento e explicação da dinâmica e funcionalidade dos diferentes tipos de solos que integram as paisagens terrestres.

A disciplina de Pedologia é ofertada pelo Departamento de Geografia (DGE) da Universidade Federal do Rio Grande do Norte (UFRN), sendo ministrada pela professora Dra. Zuleide Maria Carvalho Lima, nos turnos matutino e noturno, para as turmas do curso de graduação em bacharelado e licenciatura em Geografia, respectivamente.

Diante da sua peculiar relevância desempenhada como ciência, torna-se de suma importância que seu ensino proporcione condições reais de aprendizado e fixação do conhecimento, algo adquirido através da realização de observações empíricas, utilização de experimentos práticos e posteriores discussões a cerca dos mesmos.

Objetivou-se com este trabalho avaliar a importância da utilização de atividades práticas para aprimorar o ensino em Pedologia. Em termos específicos pretendeu-se analisar se de fato a utilização de atividades práticas na disciplina de Pedologia é necessária para assimilar melhor os conteúdos trabalhados teoricamente; avaliar a percepção dos alunos sobre a importância dessa metodologia no processo de ensino-aprendizagem na disciplina; analisar o grau de motivação e inibição dos discentes nas aulas práticas; averiguar a satisfação ou frustração dos discentes com o auxílio fornecido pela monitora de Pedologia. No percurso metodológico, aplicamos questionários e realizamos uma avaliação de experiências adquiridas em sala de aula. Este estudo é necessário para buscar o aperfeiçoamento do processo de ensino-aprendizagem em Pedologia, servindo como base norteadora.

Os resultados obtidos por meio dessa pesquisa se configuram de imprescindível relevância para a avaliação da metodologia adotada em sala de aula e do papel desempenhado pela monitora da disciplina. As críticas e respostas favoráveis ou não à metodologia pedagógica utilizada nas aulas contribuem de forma construtiva no aprimoramento de aulas futuras.

\section{METODOLOGIA}

A metodologia adotada para construção do conhecimento continuado na disciplina de Pedologia, 
envolve aulas teóricas, de campo e de laboratório. Em campo, são realizadas análises de diferentes perfis de solos a partir da realização de tradagens (FIGURA 01) e da caracterização morfológica dos mesmos (FIGURA 02) para isso, os discentes são devidamente equipados, instrumentalizados e orientados pela docente e a monitora, havendo uma troca mútua de conhecimento entre os participantes da turma.

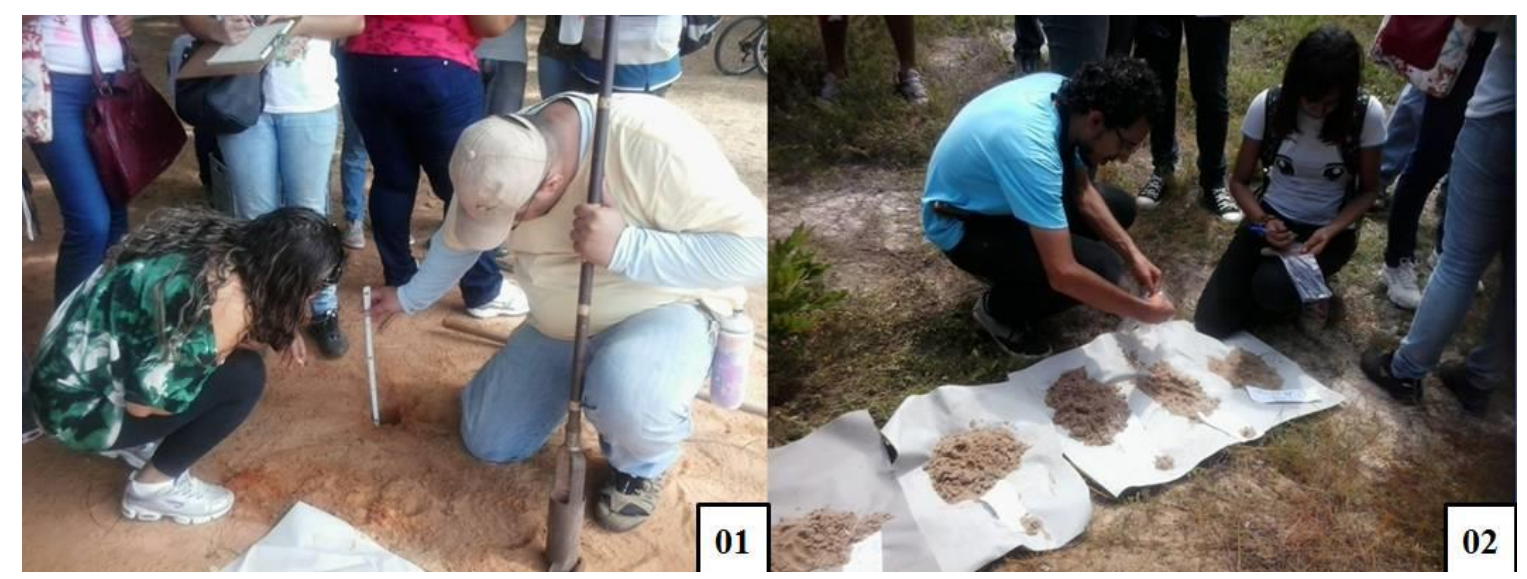

FIGURAS 01 e 02: Alunos realizando tradagem e caracterização morfológica do solo.

Fonte: Ivaniza Sales Batista (2012).

A sondagem feita através de tradagem é ligeira e pode ser executada tanto de forma manual quanto mecanicamente, utilizando trados de caneca, holandês, espiral etc. Retira amostras de solo deformadas em bom volume e com pequeno alcance chegando até 15 metros. A descrição de diferentes perfis de solos, é fundamental, possibilitando aos alunos a oportunidade de visualizar distintas características intrínsecas a cada perfil, condicionadas pelos diferentes contextos de formação e processos (físicos, químicos e antrópicos) atuantes.

É interessante ressaltar que o uso do trado apresenta algumas vantagens em relação ao seu uso, pois ele é uma forma de coleta rápida e barata, com o qual se colhe um volume razoável de amostras, suficientes para a realização de ensaios de caracterização, além de não exigir equipamentos nem mão de obra especializada. Já as desvantagens estão relacionadas à pouca profundidade dos furos, impossibilitando a retirada de amostras indeformadas, permitindo somente a realização de ensaios onde a estrutura de amostragem não precisa ser preservada.

Em laboratório, os alunos são divididos em grupos para pesquisar sobre os atributos morfológicos dos solos (cor, textura, estrutura, nódulos, concreções, cerosidade, consistência, porosidade, permeabilidade e transição entre horizontes) e apresentar, posteriormente, seminários de caráter prático e ilustrativo. Cada grupo fica responsável por trazer amostras que represente o seu respectivo parâmetro morfológico e fazer observações, ressalvas e indagações sobre suas características e peculiaridades, sobretudo no que se diz respeito à sua identificação em campo e 
interpretação. Para maior comodidade e praticidade, esses seminários são realizados nos laboratórios de geografia física da universidade, o qual fornece o apoio e espaço que as atividades exigem.

No Laboratório de Geografia Física (LABGEOFIS), situado no DGE, são realizados os métodos de peneiramento (para a determinação das classes de areia) e pipeta (para determinação de silte e argila - DIAS, 2004; SUGUIO, 2003; LIMA, 2004) para a análise da textura do solo, diante da disponibilidade de equipamentos no mesmo. Já no Laboratório de Geografia Física, situado no Setor de Aulas II, da UFRN, são realizadas as demais análises morfológicas do solo a partir da exposição dos seminários práticos.

A monitoria serve como um apoio aos discentes na busca, reunião e elaboração de materiais, assim como, no equacionamento de eventuais dúvidas dos mesmos, auxiliando na mediação entre eles e o corpo docente, tendo em vista que muitos dos alunos se sentem inibidos em procurar a professora da disciplina para exporem suas dúvidas, opiniões, sugestões e anseios, achando melhor procurar a monitora da mesma - por também se tratar de uma aluna em processo de formação.

Em suma, para avaliar a metodologia adotada nas aulas de Pedologia realizamos uma avaliação das experiências adquiridas em sala de aula, somada a aplicação de questionários com perguntas pontuais, específicas e objetivas, cujo público alvo foi composto pelos discentes que cursaram, nos períodos letivos de 2012.1 e 2012.2, a disciplina de Pedologia, totalizando 64 alunos, já que ambas as turmas apresentaram o total de 32 discentes matriculados.

\section{RESULTADOS E DISCUSSÃO}

O solo é um importante recurso natural, entendido como material intemperizado e inconsolidado que recobre o manto terrestre, resultante da ação ativa e integrada do clima e dos organismos vivos (incluindo o homem) sobre um material de origem, em determinadas condições geomorfológicas no transcorrer do tempo (USDA apud FLORES; RIBASKI; MATTE, 2010).

Salienta-se que o solo é "[...] princípio e fim de todas as coisas, sustentáculo das civilizações, principal fonte de alimento e matérias primas, palco das diversidades, testemunha de duelos históricos, moeda de uso e troca". (PERUSI; SENA, 2012, p. 156). Perante o papel desempenhado do solo na vida do homem, o estudo da ciência do solo é primordial para sua proteção e conservação, constituindo-se como garantia da manutenção de meio ambiente sadio e auto-sustentável (SILVA; RIBEIRO, 2004).

Vislumbra-se, no meio acadêmico o crescente número de trabalhos direcionados à discussão do ensino do solo e sua importância, conforme percebido em Silva e Ribeiro (2004), Perusi; Sena (2012), Frasson; Werlang (2010), Gonzales; Barros (2000), Silva; Falcão; Sobrinho 
(2008), Lima (2005). Por essas razões, o conhecimento das particularidades desse imprescindível recurso natural é indispensável, principalmente, na formação de geógrafos e profissionais afins. Nessa perspectiva, seu ensino deve proporcionar condições reais de aprendizado e consolidação do mesmo.

Através de reflexões e análises acerca das experiências adquiridas com o passar dos semestres na sala de aula, constatamos que a maioria dos alunos assimilou melhor as aulas teóricas a partir de atividades lúdicas, expositivas e práticas, frequentando os laboratórios de geografia física para assistir seus colegas apresentado seminários de caráter prático - com a presença de experimentos, representações e ilustrações de modo a possibilitar à turma a oportunidade de entrar em contato com características específicas dos solos que são observadas em campo.

Tendo em vista que os discentes se configuram mais participativos e atenciosos e menos inibidos, fazendo indagações tanto ao grupo que por ventura estava apresentando quanto à professora e à monitora da disciplina, as quais rendiam mais questionamentos, de modo a desencadear discussões pertinentes e favoráveis à construção do amadurecimento acadêmico das partes envolvidas.

No período de elaboração e reunião de materiais para a realização dos seminários constatouse uma maior demanda de alunos procurando a monitora da disciplina para dirimir eventuais dúvidas e pedir orientações de onde e como identificar e conseguir amostras representativas do seu respectivo tema de apresentação, para mostrar aos seus colegas de turma. Isso acontece, talvez, porque os alunos se sentem mais a vontade a se direcionar ao aluno monitor do que a professora da disciplina, por também se tratar de um aluno em processo de formação, somado a menor disponibilidade do professor para atender os alunos.

Não foi possível obter as repostas de todo o público-alvo dessa pesquisa, devido a não localização de alguns, a pouca vontade de outros e o trancamento da disciplina efetivado por uns poucos. Mas a maioria (56, no total) contribuiu com o fornecimento de respostas plausíveis para a realização desse trabalho.

A pergunta inicial do questionário aplicado, buscou saber como os discentes avaliava a realização de atividades práticas na apreensão dos conteúdos trabalhados teoricamente em sala de aula. Dois terços dos alunos avaliaram como essencial, enquanto que um menor número de alunos atestou indiferença (FIGURA 03). 
1 - Como avalia a realização de atividades práticas na disciplina de Pedologia?

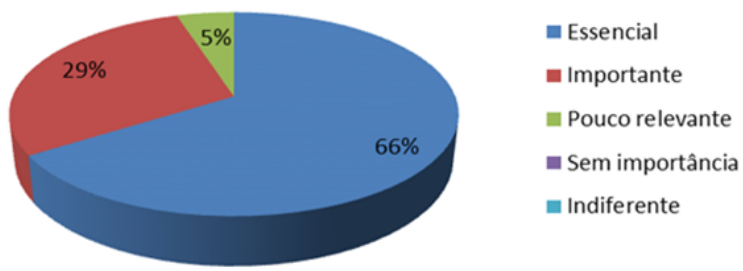

FIGURA 03: Resultados da aplicação de questionários.

Fonte: Ivaniza Sales Batista (2012).

Posteriormente, foi questionado ao aluno a respeito da assimilação dos conteúdos da ciência do solo. A maioria respondeu que assimilou melhor os conteúdos trabalhados teoricamente em Pedologia indo ao laboratório e realizando atividades práticas. Contudo, ressalta-se que uma pequena parcela dos discentes respondeu negativamente à indagação, um dado a se pensar sobre quais as dificuldades enfrentadas por esses alunos durante as atividades práticas (FIGURA 04).

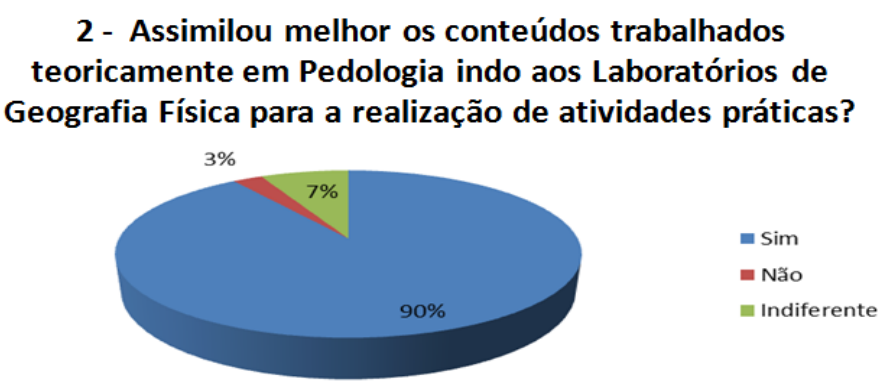

FIGURA 04: Resultados da aplicação de questionários. Fonte: Ivaniza Sales Batista (2012).

Questionou-se, então, a respeito da apreensão do conhecimento na disciplina a partir da realização de atividades práticas. Pouco menos da metade da turma, respondeu que as atividades práticas contribuíram muito para a melhor e mais eficiente compreensão do conhecimento, pouco mais de um terço afirmaram que sim, enquento $4 \%$ dos alunos posicionaram indeferentes e negativamente(FIGURA05).

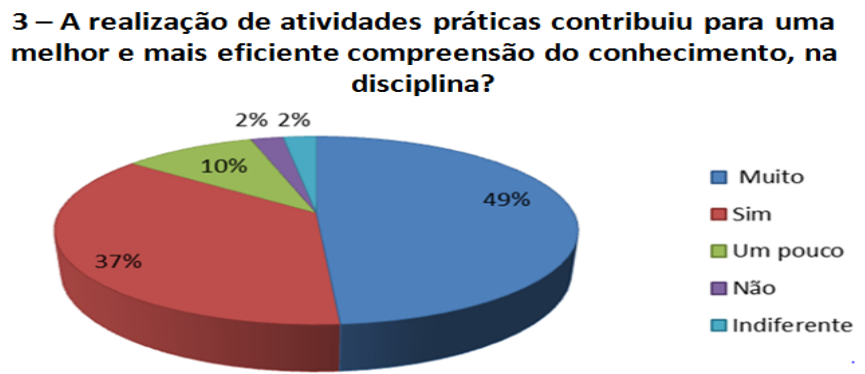

FIGURA 05: Resultados da aplicação de questionários. Fonte: Ivaniza Sales Batista (2012). 
A maioria dos discentes atestaram apresentar maior motivação nas aulas de Pedologia quando as mesmas possibilitaram a oportunidade de apreender os conteúdos trabalhados em ambiente laboratorial e em campo. Evidenciando a importância dessas práticas para maior aproveitamento da disciplina, por parte dos envolvidos (FIGURA 06).

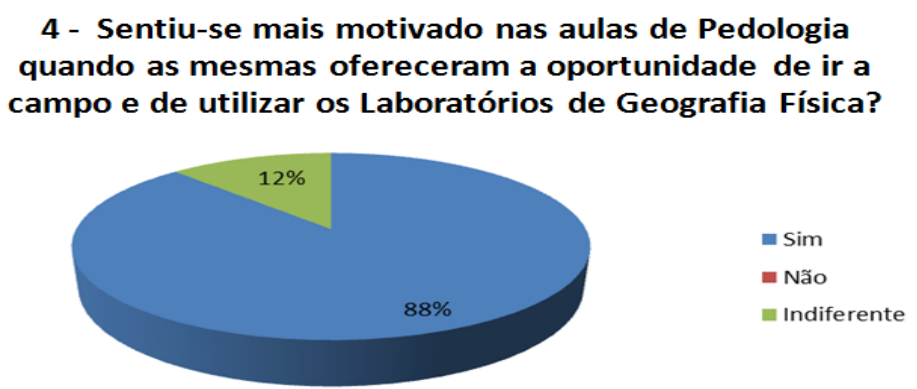

FIGURA 06: Resultados da aplicação de questionários.

Fonte: Ivaniza Sales Batista (2012).

Quanto à inibição, os resultados demosntram que mais de um terço do público-alvo apresentou inibição para fazer questionamentos e emitir opiniões durantes as aulas práticas, um percentual bastante expressivo (FIGURA 07). Esse dado reflete a heterogeneidade e a personalidade das turmas, somadas ao não êxito pleno dos desafios impostos à docente e à monitora da disciplina.

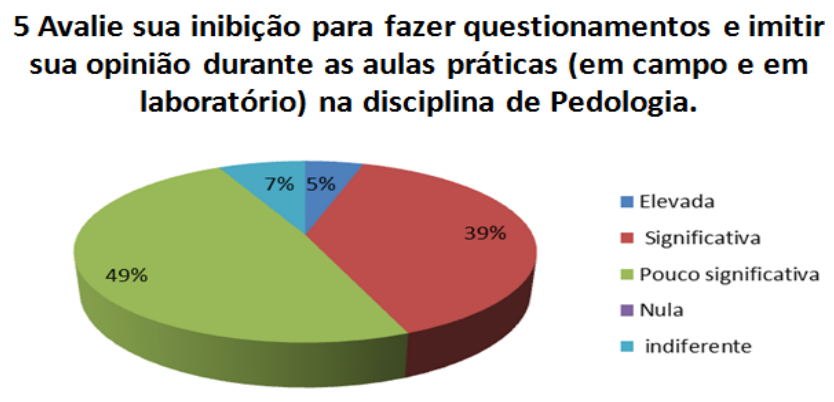

FIGURA 07: Resultados da aplicação de questionários.

Fonte: Ivaniza Sales Batista (2012).

Por fim, indagou-se sobre a importância da monitora da disciplina na realização das atividades práticas (em campo e laboratório). Os dados evidenciam a não abrangência total dos discentes por parte da monitora. Refletindo, talvez, a inexperiência em sala de aula e suas limitações de conhecimento (FIGURA 08). 


\section{6 - A monitora da disciplina foi de alguma importância na realização das aulas práticas (em campo e laboratório)?}

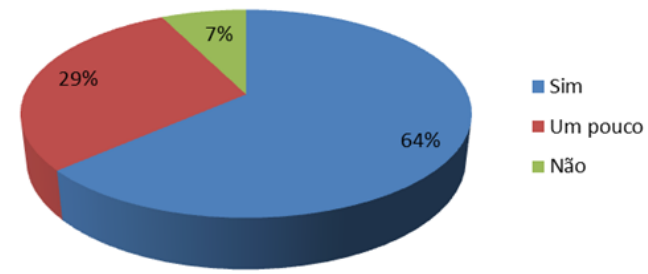

FIGURA 08: Resultados da aplicação de questionários. Fonte: Ivaniza Sales Batista (2012).

Em suma, a aplicação de questionários serviu para comprovar, reforçar e demonstrar o quão significativo e construtivo se configuram a efetivação de aulas de campo e os seminários de caráter prático - em laboratório - no processo de ensino em Pedologia. Embora, haja ressalvas importantes a serem consideradas e aspectos a serem aprimorados no processo de ensino-aprendizagem. Essas práticas, possibilitam assimilação e apreensão melhores das aulas teóricas, além de abrir espaço para a realização de trocas de saber entre o corpo docente e discente (com auxílio da monitora), tornando fundamental na absorção, construção e aperfeiçoamento do conhecimento da ciência do solo.

\section{CONSIDERAÇÕES FINAIS}

O solo é um recurso natural essencial para a vida no ecossistema terrestre, é dele que retiramos boa parte dos alimentos e matérias primas que necessitamos, sobre ele as atividades práticas espaciais desenvolvem-se. Nesse sentido, ressalta-se a importância de apreendê-lo, para promover sua manutenção e conservação de seus recursos.

Seu ensino deve proporcionar condições reais de aprendizado, sobretudo, nos cursos de graduação em geografia e cursos afins. Na tentativa de promover maior aproveitamento e compreensão dos conteúdos teóricos trabalhados em sala de aula, propomo-nos a realização de atividades práticas (em campo e laboratório) com os discentes de Pedologia.

Os alunos demonstraram assimilar melhor os conteúdos trabalhados teoricamente em sala de aula, a partir da adoção dessa metodologia de caráter eminentemente prático. A aplicação de questionários com turmas anteriores possibilitou um feedback dos discentes sobre o modo como a disciplina vem sendo trabalhada. Os resultados, obtidos em sua maioria, foram positivos, mas temos muito o que aprimorar, no que se concerne, à metodologia aplicada, um eficiente aproveitamento da mesma pelos envolvidos (corpo docente e discente). 
Portanto, podemos aferir que o desenvolvimento de atividades como essas é de extrema valia para a construção e assimilação do conhecimento na ciência do solo. A oportunidade de observação in loco, princípio básico da disciplina, juntamente, com as atividades práticas em laboratório, permitem melhor aferição dos conteúdos e tornam os alunos mais motivados, interessados, participativos e relativamente menos inibidos.

\section{REFERÊNCIAS}

DIAS, J. A. Análise sedimentar e o conhecimento dos sistemas marinhos - Universidade de Algarves, 2004.

EMBRAPA - Empresa Brasileira de Pesquisa Agropecuária. Disponível em: <http://www.embrapa.br/>. Acesso em: 21, abr. 2014.

FLORES, Carlos Alberto; RIBASKI, Jorge; MATTE, Vilmar Luciano. Sistema agrossilvipastoril na região sudoeste do estado do Rio Grande do Sul. In: Empresa Brasileira de Pesquisa $\begin{array}{llll}\text { Agropecuária } & - & 2010 . & \text { EMBRAPA, }\end{array}$ em<http://www.infoteca.cnptia.embrapa.br/bitstream/doc/870878/1/Sistemaagrossilvipastorilnaregi aosudoestedoestadodoRioGrandedoSul.pdf>. Acesso em: 21, abr, 2014.

FRASSON, V. da R; WERLANG, M. K. Ensino de solos na perspectiva da educação ambiental: contribuições da ciência geográfica. 2010. Geografia: Ensino \& Pesquisa, Santa Maria, v. 1 4, n. 1 , p. 94- 99, 2010.

GONZALES, S. L. de M. BARROS, O. N. F. O ensino de pedologia no ciclo básico de alfabetização. Geografia, Londrina, v. 9, n. 1, p. 41-49, jan./jun. 2000.

IBGE - Instituto Brasileiro de Geografia E Estatística. Manual técnico de pedologia. Coordenação de Recursos Naturais e Estudos Ambientais. 2 ed. Rio de Janeiro: IBGE, 2007. 316 p. Disponível em: <http://biblioteca.ibge.gov.br/visualizacao/livros/liv37318.pdf>. Acesso em: 21, abr. 2016.

LIMA, Z. M. C. Caracterização da dinâmica ambiental da região costeira do município de Galinhos, litoral setentrional do Rio Grande do Norte. Tese (Doutorado em Geodinâmica) Programa de Pós-Graduação em Geodinâmica e Geofísica da Universidade Federal do Rio Grande do Norte, Natal, 2004.

LIMA, M. R. de. O solo no ensino de ciências no nível fundamental. Ciência \& Educação, v. 11, n. 3, p. 383-394, 2005.

QUEIROZ NETO, J. P. de. Pedologia: conceito, método e aplicações. Revista do Departamento de Geografia, [S.1.], v. 3, p. 95-102, nov. 2011. Disponível em: <http://www.revistas.usp.br/rdg/article/view/47088>. Acesso em: 12 fev. 2016. 
PERUSI, M. C. SENA, C. C. R. G. de. Educação em solos, educação ambiental inclusiva e formação continuada de professores: múltiplos aspectos do saber geográfico. Entre-Lugar, Dourados, MS, ano 3, n.6, p 153 - 164, 2. 2012.

SUGUIO, Kenitiro. Geologia sedimentar. São Paulo: Edgar Blüncher, 2003.

SILVA, A. C. da. RIBEIRO, A. L. da S. A disciplina pedologia ministrada nos cursos de geografia em diversas cidades maranhenses por meio do PROCAD. Geografia. Londrina, v. 13, n. 1 jan./jun. 2004. Disponível em <http://www.geo.uel.br/revista>. Acesso em: 20 abr. 2016.

SILVA, C. S. da. FALCÃO, C. L. da C. SOBRINHO, J. F. O ensino do solo no livro didático de geografia. Revista Homem, Espaço e Tempo. Centro de Ciências Humanas da Universidade Estadual Vale do Acaraú/UVA. Ano II, número 1, mar. 2008.

Recebido em: 14/08/2016

Aceito para publicação em: 01/10/2016 